\title{
Дрыгина Ю.А.
}

\section{МЕТАФОРИЧЕСКОЕ ПРЕДСТАВЛЕНИЕ БАЗОВОГО КОНЦЕПТА} УПРАВЛЕНЧЕСКОГО ДИСКУРСА

доцент кафедры английской филологии и межкультурной коммуникации, кандидат филологических наук, доцент Белгородский государственный национальный исследовательский университет (НИУ «БелГУ»), ул. Победы, 85, г. Белгород, 308015, Россия. E-mail: drygina@ bsu.edu.ru

\begin{abstract}
Аннотация
Данная статья посвящена рассмотрению базового концепта управленческого дискурса концепта «Власть». Ее основной целью является представление того как власть репрезентируется в языке. Анализ вербализации концепта «Власть» в английском языке проводится при помощи рассмотрения концептуальных метафор, лежащих в основе управления. Метафора представляется своеобразным инструментом исследования дискурса, с помощью которого человек получает возможность осмысливать довольно сложные и неизученные предметные области, используя имеющиеся у него знания и опыт. В статье выявляются метафорические модели, описывающие власть, ее особенности и характер ее действий в русском и в английском языках («Обладающий властью находится сверху», «Подчиненный находится снизу», «Обладать властью значит удерживать что-то или кого-то», «Обладание властью сродни управлению транспортным средством или животным» и другие). Это позволяет подчеркнуть универсальный характер власти и ее понимания в русской и английской лингвокультурах.
\end{abstract}

Ключевые слова: управленческий дискурс; когнитивная метафора; концепт

Drygina Yu.A.

METAPHORIC REPRESENTATION OF THE BASIC CONCEPT OF MANAGEMENT DISCOURSE

$\mathrm{PhD}$ in Philology, Associate Professor, Department of English Philology and Cross-cultural Communication, Belgorod State National Research University, 85 Pobeda St., Belgorod, 308015, Russia. E-mail: drygina@bsu.edu.ru

\begin{abstract}
This article deals with the analysis of the management discourse basic concept "Power". Its main goal is to present how power is represented in the language. The analysis of the verbalization of the concept "Power" is carried out with the use of conceptual metaphors that underlie management. Metaphor is represented as a means of discourse analysis. Conceptual metaphor enables people to comprehend rather difficult and unstudied spheres using their knowledge and experience. The article reveals some metaphoric models describing power and its peculiarities in Russian and in English. They are "Having power is like being in a higher position", "Not having power is like being down", "Having power is like driving a vehicle or controlling an animal", "Having power is like holding someone or something," and others. This enables to emphasize universal features of power and its understanding in Russian and English linguocultures.
\end{abstract}

Key words: management discourse; cognitive metaphor; concept.

\section{Введение}

Исследование концептов и особенностей их вербализации является на протяжении последних десятилетий доминантой в современной лингвистике. Рассматриваются, как правило, концепты в языке, базовые концепты в творчестве отдельных авторов или литературных произведениях. Существует также немало исследований, посвященных изучению центральных концептов различных дискурсивных жанров.
Базовые концепты лежат в основе и, соответственно, определяют тип институционального дискурса. Так, в медицинском дискурсе к таким концептам можно отнести «болезнь» и «врач», в педагогическом дискурсе «педагог» и «образование», в юридическом «закон», в политическом - «политик» и «власть». Последний концепт мы считаем базовым и для управленческого дискурса, который, как представляется, объединяет в себе такие дискурсивные жанры, как политический, деловой, 
педагогический дискурс. Данный концепт уже рассматривался в работах отечественных лингвистов $[1,3,6,12,14]$.

Интерес именно к данному концепту объясняется тем, что власть принадлежит, к числу естественно-общественных явлений, вызванных к жизни объективными условиями существования людей, что делает его исследование актуальным. Проблемы власти всегда относились к числу наиболее актуальных проблем общественного развития, поскольку в любом обществе вопрос о власти является приоритетным. К тому же данный концепт является центральным для многих общественных дисциплин - социологии, политологии, философии.

\section{Основная часть.}

При рассмотрении языковых особенностей концепта трудно не согласиться с В. И. Карасиком в том, что центральные концепты, образующие основу общественных институтов, обладают большой генеративной силой в том плане, что вокруг них концентрируется обширная смысловая область [7, с. 6].

Помимо анализа семантики лексем, репрезентирующих концепты, самым точным и единственно доступным способом проникновения в содержание концепта, выявить те ментальные модели, которые позволяют организовывать представление и хранить в человеческой памяти знания о предметах и явлениях действительности.

Вслед за Е. И. Шейгал, мы полагаем, что проблема соотношения языка и власти имеет два аспекта: 1) как власть осмысляется, концептуализируется языком; 2) как власть проявляется через язык [14, с. 95].

\section{Цель работы.}

Целью данной статьи является представление особенностей репрезентации в современном английском языке концепта власти, что соотносится с первым из обозначенных выше аспектов соотношения языка и власти.

\section{Материалы и методы исследования.}

Анализ репрезентации концепта «Власть» в английском языке проводится при помощи рассмотрения концептуальных метафор, лежащих в основе управления, поскольку исследование закономерностей метафорического моделирования действительности стало одним из важнейших направлений современной когнитивной лингвистики.

Одним из первых фундаментальных трудов, посвященных изучению концептуальных метафор, является исследование Дж. Лакоффа и
М. Джонсона. Они полагали, что метафоры пронизывают всю нашу жизнь не только в языке, но и в мышлении, и в действии. Наша обыденная понятийная система, в рамках которой мы мыслим и действуем, метафорична по самой своей сути. [15, с. 3$]$.

Они выделили в английском языке целые системы метафор, основывающиеся на принятых в англоговорящих странах точках зрения на те или иные объекты обозначения, назвав такие метафоры концептуальными.

В отечественной лингвистике существует целый ряд работ, посвященных в том числе истории развития и основным положениям теории концептуальной метафоры. Это труды А. Н. Баранова и Д. О. Добровольского [2], В. 3. Демьянкова [4], Е. С. Кубряковой [8, 9], Е. В. Рахилиной [10], Т. Г. Скребцовой [11] и целого ряда других авторов.

Их объединяет идея о том, что метафора является не только объектом изучения, но и одновременно с этим своеобразным инструментом исследования дискурса.

Проводя анализ политического дискурса А. Н. Баранов отмечает, что именно метафора позволяет выявить способы, с помощью которых в текстах интерпретируются те или иные явления, события, социальные отношения, имеющее ключевое значение для понимания протекающих социально-политических процессов. С помощью метафоры человек получает возможность осмыслять довольно сложные и неизученные предметные области, используя имеющийся у него фонд знаний опыт взаимодействия с окружающим миром [1. с. 4].

Аналогичной точки зрения придерживается и А. П. Чудинов, подчеркивая, что современная когнитивная лингвистика считает метафору не тропом, призванным украсить речь и сделать образ более понятным, а формой мышления [13]. Он высказывает важную для нашего исследования мысль о том, что в коммуникативной деятельности метафора важное средство воздействия на интеллект, чувства и волю адресата что делает анализ метафорических образов способом изучения ментальных процессов и постижения индивидуального, группового и национального самосознания.

Принимая во внимание все вышеизложенное, трудно не согласиться с О. В. Дехнич в том, что метафора не просто является риторической фигурой, а служит существенной необходимостью мысли. Результат всей духовной активности 
человека, сумма всех его представлений о мире образуют для; человека целостную картину мира, которая отражается в языке, формируя языковую картину мира [5, с. 40].

Кроме исследований, рассматривающих теорию метафоры в общем есть немало работ, посвященных изучению политической метафоры и метафорического представления власти в русской и английской лингвокультурах. Обратимся к некоторым исследованиям.

А. П. Чудинов исследует политическую метафору на материале русского языка. Он последовательно описывает четыре важнейшие понятийные сферы-источники метафорической экспансии в русском политическом дискурсе («Человек и природа», «Человек и общество», «Человек и результаты его труда», «Человек как центр мироздания») [13]. Автор исследует проблемы инвентаризации и систематизации метафорических моделей, рассматривает политическую метафору в контексте, тексте и дискурсе. Каждая из рассмотренных метафор (физиологическая метафора, морбиальная метафора метафора родства, сексуальная метафора и др.) является мелкой деталью в огромной мозаике, но подобные образы - это реализация действительно существующих в общественном сознании моделей, однако метафорическое зеркало, как подчеркивает автор отражает не реальное положение дел в России, а его восприятие в национальном сознании.

А. Н. Баранов [1] исследует особенности метафорического осмысления отношений бизнеса и власти. В качестве метода исследования был выбран лингвостатистический анализ корпуса текстов, в результате которого была выявлена частота использования метафорических моделей, а лингвостатистический анализ корпуса метафор позволил сгруппировать отобранные метафоры по метафорическим моделям и определить частотность их использования. Было выявлено более 30 метафорических моделей среди которых наиболее частотными оказались модели персонификации, ограничителя, объекта и предмета, пространства, света и тени и целый ряд других. Анализ моделей показал как представители бизнес-сообщества концептуализируют действия власти.

Метафорические модели, описывающие власть и характер ее действий по отношению к бизнесу - это модели «вещество», «война», «геометрия», «движение», «игра», «история», «коммуникация», «механизм», «объект», «предмет», «ограничитель», «организм», «охота», «персонификация», «преступный мир», «пространство», «свет», «тень», «система», «спорт», «строение», «театр», «транспорт», «фауна», «физическое действие», «финансы».

Интересным и важным для нашего исследования является вывод автора о том, что идея доминирования власти в сложившихся взаимоотношениях с бизнесом очень четко профилируется с помощью целого ряда моделей метафорической модели пространства, которая интерпретирует политику как структурированное пространство с четко определенным положением каждого из участников, модели персонификации, которая в дискурсе высвечивает идею противопоставления человека активного и человека пассивного, причем власть всегда выступает в роле доминирующей, воздействующей стороны, модели физическое действие, также отражающей ограничительный характер действия власти.

В работе В. И. Карасика проводится анализ ряда институциональных концептов, в том числе концепта «Власть». Он отмечает, что власть изображается в виде пространственной метафоры, изображается как далеко проникающие щупальца большого и сильного организма, однако имеет определенные ограничения, выход за которые невозможен. Он также приводит примеры сравнения власти с определенным снадобъем и сравнения власти и сексуального чувства, основанного на ощущении силы [7, с. 60].

В своем интересном глубоком исследовании Е. И. Шейгал [14] подробно рассматривает метафорику лексемы власть и устанавливает целый ряд метафорических моделей власти.

Во-первых, власть - это объект отчуждаемой принадлежности, который может быть объектом приобретения, передачи, утраты, а также добычи и завоевания (иметь, получить, передать, захватить власть; перехват, передел власти; possess, take, seize, keep, transfer, cede power, interchanges of power).

Власть предстает в виде вычлененного из пространства компактного физического предмета, с четкими границами. Выделенность данного объекта в пространстве позволяет описывать движение и местонахождение субъектов относительно него (восхождение к власти, вхождение во власть, стоять у власти, идти к власти; rise, climb to power, stay in power, be out of power).

Власть имеет пространственные параметры форму и ее геометрические характеристики (пирамида власти, треугольник власти, вершина 
власти, властная вертикаль; line, angles, centers of power), размер/масштабы (безмерная, огромная, большая, неограниченная, ограниченная власть, объем власти, превышение власти, полнота власти; immense, ultimate, huge, exclusive power), вес (сила/слабость власти, бремя власти; власть тяготит, довлеет, обременяет; burden, concentration of power).

Власть представляется также в виде открытого пространства значительной протяженности, в пределах которого существуют и действуют субъекты и объекты политики, разворачиваются политические события и действия (поле, ареал, арена власти; властное пространство; горизонты, границы, пределы власти, магистраль власти; avenues of power, extension of power).

Восприятие власти как физического объекта реализуется также через метафору архитектурного сооружения, которая подчеркивает ее рукотворный характер (здание власти строится человеком) архитектура власти, каркас власти, фасад власти, фундамент, опора власти, лабиринты, коридоры власти, кулисы власти, демонтаж власти; halls, corridors of power). C метафорой здания/конструкции связан признак прочности прочность, незыблемость власти, укрепление власти, поколебать, подорвать власть; bases of power, consolidate, crash power).

Весьма распространенной является метафора механизма, при помощи которой человек представляет себе процесс функционирования власти (рычаги, руль, пульт управления, часовой механизм, пружина власти, машина власти).

Власть предстает как нечто естественно существующее - живое существо, явление природы (корни, ветви, недра власти; расцвет, мутации, перерождение власти), при этом особенно распространенной для описания неудовлетворительного состояния дел является метафора болезни (болезни власти, температура власти была; пульс власти, атрофия /дистрофия власти, паралич власти, немощь власти, агония власти, коллапс власти)

Отмечает автор и текучесть, преходящий характер власти (истоки власти, каналы власти; сохранение, стабильность, стабилизация власти; фазы власти; ускользающая власть; падение, фиаско власти; elusiveness of power, source of power).

Для власти характерна метафора персонализации (власть имеет лицо, черты, почерк, она достигает зрелости и совершает жизненный цикл).
Результаты исследования и их обсуждение.

Как видно, проблема метафоризации власти очень подробно рассмотрена на материале русского языка.

Уже указанные метафорические модели мы находим и в английском языке.

Первую концептуальную метафору, связанную с властью, можно условно назвать «Обладающий властью находится сверху».

Обратимся к примерам реализации данной метафоры:

They have no power/control over their staff.

She ruled over the empire for many years.

He remained at the top for ten years, until his retirement.

They have come out on top yet again.

She holds the highest position in the company [16].

Как видно в приведенных примерах значение нахождения сверху передается при помощи предлогов места (over), глагола с послелогом (ruled over), при помощи лексических средств (at the top, on top, the highest position).

Следующая концептуальная метафора антонимична предыдущей и звучит как «Подчиненный находится снизу», например:

There are many staff under her.

How many people are there above you?

I began my career as a lowly office worker.

Don't let them walk all over you.

the upper / lower classes

They were downtrodden and oppressed.

She's completely under his thumb [16].

Как видно из приведенных примеров способы реализации метафоры практически не отличаются.

Следующая концептуальная метафора может быть условно названа «Обладать властью значит удерживать что-то или кого-то» и представлена следующими примерами с фразеологическими сочетаниями:

They have a hold over him.

The military forces seized power.

Police kept a firm grip on dissenters.

She seems to have a handle on most of the work.

I've got the situation well in hand.

The children are completely out of hand [16].

И, наконец, последняя из рассматриваемых в данной статье концептуальная метафора это «Обладание властью сродни управлению транспортным средством или животным». Она представлена в языке как фразеологическими сочетаниями, так и фразеологическими единствами и сращениями, например: 
Who makes the decisions?

Who is pulling the strings?

I have no idea who's in the driving seat.

The company expanded greatly during his years in the saddle.

She is steering the country through muchneeded reforms.

She kept her staff on a very tight rein [16].

Метафорические модели пространства, физического действия и механизма являются, как видно из приведенного анализа, ведущими, как в русском, так и в английском языке, что подчёркивает универсальный характер власти и еe восприятия в русской и английской лингвокультурах.

\section{Список литературы}

1. Баранов А. Н. Некоторые константы русского политического дискурса сквозь призму политической метафорики ('взаимоотношения бизнеса и власти', 'коррупция') / Баранов А.Н., Михайлова О.В., Шипова Е.А. Москва: Фонд ИНДЕМ, 2006. 84 с.

2. Баранов А. Н., Добровольский Д. О. Постулаты когнитивной семантики // Известия АН. Сер. лит. и яз. Т. 56. № 1. 1997.

3. Бубнова И. А. Психолингвистический анализ индивидуальной специфики концепта абстрактного понятия власть // Вестник Минского гос. лингв. ун-та. Сер 1. Филология . № 1(17) 2005. С. 7-18.

4. Демьянков В. 3. Когнитивная лингвистика как разновидность интерпретирующего подхода // Вопросы языкознания. № 4. 1994.

5. Дехнич О. В. Концептуальная метафора People are trees в современном английском языке : дисс. канд. филол. наук : 10.02.04. Белгород, 2004. 157 с.

6. Карасик В.И. Религиозный дискурс // Языковая личность: проблемы лингвокультурологии и функциональной семантики. Волгоград: Перемена, 1999. C. 5-19.

7. Карасик В. И. Языковые ключи М. Гнозис, 2009. $406 \mathrm{c}$.

8. Кубрякова Е. С. Начальные этапы становления когнитивизма: лингвистика - психология когнитивная наука // Вопросы языкознания. № 4, 1994.

9. Кубрякова Е. С. Семантика в когнитивной лингвистике // Известия АН. Сер. лит. и яз. Т. 58, № 5-6. 1999.

10. Рахилина Е. В. Когнитивная семантика: История. Персоналии. Идеи. Результаты // Семиотика и информатика. Вып. 36. М., 1998.

11. Скребцова Т. Г. Американская школа когнитивной лингвистики. Спб., 2000.

12. Черватюк И. С. Власть как коммуникативная категория: автореф. дис. ...канд. филол. Наук Волгоград 2006. 24 с.
13. Чудинов А. П. Россия в метафорическом зеркале: когнитивное исследование политической метафоры (1991-2000). Екатеринбург, 2001. 238 с.

14. Шейгал Е. И. Семиотика политического дискурса: дисс. д-ра филол. наук. Волгоград. 2000. $440 \mathrm{c}$.

15.Lakoff, G.; Johnson, M. Metaphors We Live By / G. Lakoff, M. Johnson. -Chicago: University of Chicago Press, 1980. XIII. 242p.

16. Macmillan English Dictionary for Advanced Learners. Macmillan Publishers Limited. Oxford. 2007. $1748 \mathrm{p}$.

\section{References}

1. Baranov A.N. Some Constants of the Russian Political Discourse through Political Metaphor ("Business and Politics Interrelations", "Corruption") / Baranov A.N., Mikhaylova O.V., Shipova E.A. Moscow: Fond INDEM, 2006. $84 \mathrm{p}$.

2. Baranov A.N., Dobrovol'skiy D.O. Cognitive Semantics Postulates // Izvestiya AN. Ser. lit. i yaz. T. 56. № 1.1997.

3. Bubnova I. A. Psycholinguistic Analysis of the Individual Peculiarities of the Abstract Concept Power // Vestnik Minskogo gos. lingv. un-ta. Ser 1. Filologiya . № 1(17) 2005. Pp. 7-18.

4. Dem'yankov V. Z. Cognitive Linguistics as a Type of Explanatory Approach // Voprosy yazykoznaniya. № 4. 1994.

5. Dekhnich O. V. Conceptual Metaphor "People are Trees" in the Modern English Language : diss. kand. filol. nauk : 10.02.04. Belgorod, 2004. $157 \mathrm{p}$.

6. Karasik V.I. Religious Discourse // Yazykovaya lichnost': problemy lingvokul'turologii i funktsional'noy semantiki. Volgograd: Peremena, 1999. Pp. 5-19.

7. Karasik V. I. Language Keys. M. Gnozis, 2009. $406 \mathrm{p}$.

8. Kubryakova E. S. Opening Phases of Cognitive Science // Voprosy yazykoznaniya. № 4, 1994.

9. Kubryakova E. S. Semantics in Cognitive Linguistics // Izvestiya AN. Ser. lit. i yaz. T. 58. № 5-6. 1999.

10. Rakhilina E. V. Cognitive Semantics: History, Scholars, Ideas, Results // Semiotika i informatika. Vyp. 36. M., 1998.

11. Skrebtsova T. G. American School of Cognitive Linguistics. Spb., 2000.

12. Chervatyuk I. S. Power as a Communicative Category: avtoref. dis. ...kand. filol. Nauk Volgograd 2006. 24 p.

13. Chudinov A. P. Russia in the Metaphorical Mirror. Cognitive Study of the Political Metaphor. (19912000). Yekaterinburg, 2001. $238 \mathrm{p}$.

14. Sheygal E. I. Semiotics of the Political Discourse: diss. d-ra filol. nauk. Volgograd. 2000. 440 p. 